\title{
Gianluigi Goggi, «La biblioteca di Voltaire»
}

\section{Franco Piva}

\section{(2) OpenEdition}

\section{Journals}

\section{Edizione digitale}

URL: http://journals.openedition.org/studifrancesi/1343

DOI: 10.4000/studifrancesi. 1343

ISSN: 2427-5856

\section{Editore}

Rosenberg \& Sellier

\section{Edizione cartacea}

Data di pubblicazione: 1 décembre 2015

Paginazione: 592-593

ISSN: 0039-2944

\section{Notizia bibliografica digitale}

Franco Piva, «Gianluigi Goggi, «La biblioteca di Voltaire»», Studi Francesi [Online], 177 (LIX | III) | 2015,

online dal 01 décembre 2015, consultato il 09 janvier 2021. URL: http://journals.openedition.org/ studifrancesi/1343; DOI: https://doi.org/10.4000/studifrancesi.1343

\section{Questo documento è stato generato automaticamente il 9 janvier 2021}

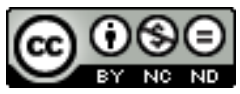

Studi Francesi è distribuita con Licenza Creative Commons Attribuzione - Non commerciale - Non opere derivate 4.0 Internazionale. 


\title{
Gianluigi Goggi, «La biblioteca di Voltaire»
}

\author{
Franco Piva
}

\section{NOTIZIA}

GIANLUIGI GOGGI, «La biblioteca di Voltaire», in Biblioteche filosofiche private. Strumenti e prospettive di ricerca, a cura di Renzo RAGGHIANTI et Alessandro SAVORELLI, Pisa, Edizioni della Normale, 2014, pp. 261-277.

1 Il volume nel quale il saggio di Gianluigi Goggi è inserito è il risultato di un progetto di ricerca, «Biblioteche dei filosofi, Biblioteche filosofiche private», sorto alcuni anni dalla collaborazione tra un gruppo di ricerca della Scuola Normale di Pisa ed il Dipartimento di Scienze Umane dell'Università di Cagliari, con l'intenzione di «agevolare con materiale di prima consultazione un aspetto particolare degli studi storico-filosofici, quello delle ricerche sulle letture dei filosofi e sul loro patrimonio librario personale» (Alessandro SAVORELLI, «Premessa», p.9). Gianluigi Goggi, dopo aver ricordato, per sommi capi, come è nata l'imponente (oltre 6000 volumi) biblioteca messa assieme da Voltaire negli ultimi vent'anni della sua esistenza (in pratica, a partire dalla sua decisione di stabilirsi definitivamente a Ferney) ed aver ricordato come quella biblioteca, acquistata dopo la morte del «philosophe» da Caterina II, è arrivata all'Ermitage, prima di passare definitivamente alla Biblioteca Nazionale Russa di San Pietroburgo, ha posto in luce, da un lato, come essa sia servita a Voltaire per completare la sua formazione filosofica e la sua informazione di storico e di polemista; dall'altro come, dopo il suo trasferimento in Russia, sia diventata essa stessa oggetto di indagini sempre più accurate. Si è trattato, prima di tutto, di ricostruire quella biblioteca nella sua interezza, visto che nel corso dei suoi vari trasferimenti, una parte dei libri che la componevano erano andati dispersi; lavoro non facile, come documenta l'autore, e non ancora concluso. Si è trattato poi di rilevare, pubblicare e studiare le note che Voltaire ha apposte, talvolta in maniera sovrabbondante, su una parte consistente dei suoi libri (oltre duemila su un totale di circa seimila) nel corso delle sue 
letture. Voltaire era un lettore molto attento ed estremamente reattivo. Leggere significava per lui confrontarsi attivamente con il libro letto, reagire ad esso sull'istante; la sua penna era in continuo movimento. Le «notes marginales» di cui i suoi libri sono, a volte, letteralmente coperti, sono di vario tipo. Per gli studiosi si è trattato, e si tratta ancora, visto che il lavoro, prossimo alla conclusione, non è stato a tutt'oggi stato ultimato, non solo di pubblicare quelle «notes» ma anche di studiarle, di capirne l'origine e la destinazione.

2 Entrare nel mondo di quelle annotazioni, ha infatti significato, e significa ancora per lo studioso di Voltaire, entrare nel mondo stesso del patriarca di Ferney, capire il suo modo di reagire agli stimoli che ogni libro offre, seguire il corso del suo pensiero, a volte ripercorrere la genesi di alcune delle sue opere più interessanti. In questa prospettiva possono essere di notevole interesse anche i cosiddetti «pots-pourris», vale a dire i numerosissimi (146) «dossiers» (articoli, estratti di libri a stampa e testi di altro genere) che Voltaire (o i suoi segretari) hanno costituito nel tempo, sulla base delle letture fatte, in vista (ma non sempre) delle opere che il Patriarche intendeva o aveva in mente di comporre. Testi compositi e, perciò, di difficile lettura ed interpretazione, questi «dossiers» costituiscono l'ultima frontiera di una biblioteca estremamente interessante e composita, e di un lettore altrettanto curioso e ricco di stimoli, quale fu il patriarca di Ferney.

Bel saggio, di facile lettura ma assai bene informato e documentato dal punto di vista bibliografico. 